\title{
Análisis de los elementos de la justicia transicional en el contexto de la democracia constitucional*
}

\author{
[Artículos]
}

\author{
Omar Huertas Díaz ${ }^{* *}$ \\ Christian Benítez Núñez ${ }^{* * *}$
}

Fecha de recepción: 4 de marzo de 2021

Fecha de aprobación: 18 de mayo de 2021

Citar como:

Huertas Díaz, O. y Benítez Núñez, C. (2021). Análisis de los elementos de la justicia transicional en el contexto de la democracia constitucional. Via Inveniendi Et Iudicandi, 16(2). https://doi.org/10.15332/19090528.6768

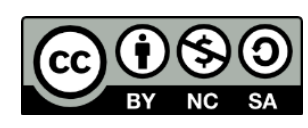

\section{Resumen}

En este artículo se realiza un estudio tanto del modelo de Estado denominado democracia constitucional, adoptado en la mayoría de los países de la región latinoamericana, como del desarrollo jurisprudencial de la Corte Interamericana, que guarda relación con los pilares de la

\footnotetext{
* Artículo resultado de investigación en el Grupo de Investigación "Red Internacional de Política Criminal Extrema Ratio UN", reconocido y clasificado por Minciencias en 2018 en A1 en el marco de cooperación de Programa de Estancias Posdoctorales en el Extranjero 2019(2) CONACYT (México). Proyecto: Tratamiento de la responsabilidad de mando de los agentes del Estado colombiano y de las FARC-EP en la comisión de crímenes de guerra, contemplada en el "Acuerdo Final para la Terminación del Conflicto y la Construcción de una Paz Estable y Duradera", Universidad Nacional de Colombia.

** Doctor en Ciencias de la Educación. Profesor titular en derecho penal, Universidad Nacional de Colombia. Investigador senior Colciencias 2018. Correo electrónico: ohuertasd@unal.edu.co; ORCID: https://orcid.org/0000-0002-8012-2387

*** Doctor en Derecho y Globalización. Sistema Nacional de Investigadores, CONACYT. Estancia Posdoctoral en el Extranjero CONACYT, UNAL. Maestro de tiempo completo, investigador B, Universidad La Salle, México. Correo electrónico: christian.benitez@lasalle.mx; ORCID: https://orcid.org/0000-0003-2559-7002
}

Via Inveniendi Et Iudicandi

e-ISSN: 1909-0528 | DOI: https://doi.org/10.15332/19090528

Vol. 16 N.o 2 | julio-diciembre del 2021 
justicia transicional: justicia, verdad, reparación y no repetición. Para ello, se atiende a una perspectiva analítica que permite exponer, de manera estructurada, aquellas directrices que precisan los alcances de las obligaciones de respeto y garantía que corresponden a los Estados que atraviesan un proceso de transición democrática en la región latinoamericana. Las conclusiones a las que se arriban en esta investigación evidencian la necesidad de crear y fomentar vías jurisprudenciales que permitan el diálogo entre Cortes y los Estadosparte, no como resultado de una obligación, sino como tendencia a una justiciabilidad directa e inmediata de los derechos humanos en favor de la consolidación de un modelo integral de Estado democrático y constitucional.

Palabras clave: justicia transicional, desarrollo jurisprudencial, corpus iuris interamericano, democracia constitucional.

\section{Analysis of the elements of transitional justice in the context of constitutional democracy}

\section{Abstract}

This article studies both the model of State called constitutional democracy, adopted in most countries of the Latin American region, and the jurisprudential development of the Inter-American Court, which is related to the pillars of transitional justice: justice, truth, reparation and non-repetition. To this end, an analytical perspective is used to present, in a structured manner, those guidelines that specify the scope of the obligations of respect and guarantee that correspond to the States that are undergoing a process of democratic transition in the Latin American region. The conclusions reached in this research show the need to create and promote dialogue between the courts and the States parties, not as a result of an obligation but as a trend towards direct and immediate

Via Inveniendi Et Iudicandi

e-ISSN: 1909-0528 | DOI: https://doi.org/10.15332/19090528

Vol. 16 N.0 2 | julio-diciembre del 2021 
justiciability of human rights for the consolidation of a comprehensive model of a democratic and constitutional State.

Keywords: transitional justice, jurisprudential development, interAmerican corpus iuris, constitutional democracy.

\section{Introducción}

Durante la segunda década del siglo XX surgieron dos leyes fundamentales que, hasta el día de hoy, inspiran al constitucionalismo de nuestros tiempos; nos referimos a la Constitución mexicana de 1917 y a la Constitución de Weimar de 1919. Ambas leyes supremas integraron un catálogo de derechos de naturaleza social que, al mismo tiempo, se reflejaron en una dimensión sustancial del constitucionalismo complementaría a la dimensión formal de la propia ley suprema. Pese a todas las conquistas legítimas que representaron los derechos reconocidos en las constituciones, lamentablemente nuestra historia latinoamericana se caracterizó por la multiplicación de regímenes autoritarios, ya sea como dictaduras plenas o como democracias simuladas.

No obstante, durante la última década de ese siglo XX, en gran parte de América Latina tuvieron lugar movimientos sociales que derivaron en múltiples transformaciones en el orden político-jurídico, desde reformas constitucionales hasta la implementación de procesos de justicia transicional, teniendo como eje la reparación de las graves violaciones a los derechos humanos de las víctimas, provocadas por los antiguos regímenes autoritarios.

Lo anterior implicó el reconocimiento progresivo de un catálogo de derechos a partir de la vigencia de un orden normativo internacional que, sin lugar a dudas, derivó en la necesidad de implementar un nuevo modelo de Estado democrático en la región, integrado por una dimensión 
formal y por otra sustancial, dando origen a la democracia constitucional, en el que el poder judicial desempeñaría un papel preponderante ante las obligaciones de respeto y garantía de los derechos humanos hasta nuestros días.

\section{Desarrollo e implicaciones del Estado de derecho a la democracia constitucional}

En este apartado, partiremos de un concepto que ha escapado de los juristas y cobrado autonomía, nos referimos al Estado de derecho. Ya sea en las noticias diarias, así como en los textos jurídicos especializados, este concepto se reproduce de manera incontrolada, y no en pocas ocasiones, ha corrido el peligro de perder su sentido.

En esa misma línea, Zagrebelsky (2011) señala que el término Estado de derecho representa un concepto abierto que ha sido llenado de diversos contenidos, atendiendo principalmente a cada época y su respectivo contexto; sirva de ejemplo que los regímenes totalitarios utilizaron este concepto para justificar la imposición de su voluntad, escapando de control alguno, de modo que "llegaba a ser irrelevante que la función desempeñada por el Estado mediante la ley fuese el dominio totalitario sobre la sociedad, en vez de la garantía de los derechos de los ciudadanos" (p. 23).

En consecuencia, Estado de derecho puede y debe analizarse desde 1) una perspectiva formal, centrada en la manera en que se promulga la ley, y en la medida en que esta es general, clara, precisa y prospectiva; y 2) una perspectiva sustancial, en la que las normas y reglas de derechos humanos constituyen una fuente de legitimidad, y, al mismo tiempo, un estándar normativo, imponiendo la obligación de guardar coherencia (Andreopoulos, Barberet y Nalla, 2018). 
Asimismo, Ferrajoli (2009) precisa que el modelo formal de Estado de derecho corresponde al modelo de Estado legislativo de derecho, en el que el principio de legalidad determina la validez de las normas, cuya producción corresponde exclusivamente al Estado. Por otra parte, en el modelo sustancial de Estado de derecho, representa al modelo de Estado constitucional de derecho, en el que cobra especial relevancia el control judicial de las leyes, ya que estas pueden ser sometidas a revisión.

Atendiendo a lo anterior, conviene preguntar: ċen qué momento de la historia cobró vigencia la dimensión sustancial del Estado de derecho? Indiscutiblemente, podemos señalar, como punto de partida, el siglo XX, cobrando mayor fuerza después de la Segunda Guerra Mundial, ya que la Constitución reivindica su función, ya no como un proyecto político de valores sin vinculatoriedad, sino como una ley suprema general que impone unas pautas de producción normativa.

Resulta entonces que la integración de una dimensión formal y una dimensión sustancial da origen a un renovado modelo de Estado constitucional de derecho, implicando una transformación en la concepción del derecho, ya que en este modelo se cuestiona la validez de las normas, atendiendo no solo a su forma de producción, sino además a su contenido (Borbón, 2019). Dicho con otras palabras, "la ley, por primera vez en la época moderna, viene sometida a una relación de adecuación, y por tanto de subordinación, a un estrato más alto de derecho establecido por la Constitución” (Zagrebelsky, 2011, p. 34).

Basta recordar a Kelsen (2001) afirmando que la Constitución representa el fundamento de las normas jurídicas, por lo tanto "cada grado del orden jurídico constituye a la vez una producción de derecho, frente al grado inferior, y una reproducción del derecho, ante el grado superior" (p. 14). Para precisar, el Estado constitucional de derecho representa un modelo de Estado que cuenta con un orden normativo coherente con las normas 
constitucionales, tendiente a organizar el poder estatal en función de la materialización de los derechos (Blanco, 2020), reconociendo a estos como la fuente de legitimidad, tanto de las normas, así como de los actos, y estableciendo mecanismos efectivos de protección y garantía.

Al llegar a este punto, tal vez se preguntarán si clo anterior representa un simple desarrollo teórico sin incidencia en la vida real? La respuesta es negativa, incluso podríamos señalar que hoy más que nunca vivimos en un contexto de constitucionalismo viviente (R. Manrique, 2019).

Bastaría con detenernos a comienzos del siglo XX e identificar dos importantes antecedentes, el primero de estos corresponde a la Constitución Política de los Estados Unidos Mexicanos de 1917, en la que se reconoce un catálogo de derechos que corresponden a una dimensión sustancial; es decir, derechos económicos, sociales y culturales, como la enseñanza libre y gratuita (art. 3), trabajo libre y justamente retribuido (art. 5), derecho a organizarse en sindicatos, y a realizar huelgas y paros (art. 123).

Continuando, el segundo de los antecedentes del constitucionalismo social corresponde a la Constitución de Weimar de 1919, al reconocer el derecho a la educación, el derecho a la libertad de trabajo, y otras tantas disposiciones establecieron obligaciones estatales frente al derecho a la salud y la seguridad social, simplemente, como ejemplo, se transcriben las siguientes disposiciones:

Art. 142. El arte, la ciencia y su enseñanza son libres. El Estado le otorga su protección y toma parte en su mantenimiento.

Art. 151. La organización de la vida económica debe responder a los principios fundamentales de justicia con el fin de asegurar para todos una existencia digna del hombre. Dentro de esos límites, la libertad económica del individuo será asegurada.

Via Inveniendi Et Iudicandi

e-ISSN: 1909-0528 | DOI: https://doi.org/10.15332/19090528

Vol. 16 N.० 2 | julio-diciembre del 2021 
Art. 161. Para la conservación de la salud y la capacidad de trabajo, para la protección de la maternidad y la previsión contra las consecuencias económicas de la vejez, de la debilidad y de las vicisitudes de la vida, creará el estado un comprensivo sistema de seguro bajo la decisiva cooperación de los asegurados (Asamblea Nacional de Weimar, 1919).

Incluso, si nos atreviéramos a dar un salto de casi siete décadas - sin dejar de advertir otros tantos acontecimientos relevantes-, señalaríamos que Colombia, en 1991, promulgó una nueva constitución política, en la que, de manera expresa, adoptó un modelo de Estado social de derecho, incorporando cláusulas de reconocimiento de derechos, reforzando un orden constitucional con base en la dimensión formal y sustancial. A manera de síntesis, precisamos lo siguiente:

- Adopción de un modelo de estado social de derecho (art. 1).

- Obligación de garantizar los principios, derechos y deberes constitucionales (art. 2).

- Obligación de proteger las riquezas culturales y naturales (art. 8).

- Reconocimiento del derecho a la paz (art. 22).

- Reconocimiento del derecho a la vivienda digna (art. 51).

- Reconocimiento del derecho a la negociación colectiva y el derecho a huelga (arts. 55 y 56 ).

- Reconocimiento del derecho a la salud (arts. 49 y 50).

Insistimos en que, desde una perspectiva integradora, los términos Estado de derecho y Estado social de derecho, se insertan en el término Estado constitucional de derecho, atendiendo a la naturaleza de este último, que tal y como lo hemos señalado, implica una recepción de cada uno de los derechos que se reconocen a través de las luchas y conquistas históricas. 
Una vez señalado lo anterior, nos parece acertado adoptar un nuevo término que integre ese multicitado catálogo de derechos y que lo hemos encontrado en la democracia constitucional. Ahora bien, este término ha sido desarrollado ampliamente por Ferrajoli (2013), de la siguiente manera:

La democracia constitucional [...] es siempre un sistema nomodinámico que incluye normas sobre la producción que, gracias a su colocación en el vértice de la jerarquía de las fuentes y las normas, son idóneas para establecer los requisitos esenciales, tanto de forma como de sustancia, de la vigencia y de la validez formal y sustancial de todas las normas producidas. (p. 17)

Continuando, Ferrajoli y Bovero (2012) identifican la existencia de dos dimensiones de la democracia: 1) una formal o procedimental para garantizar la voluntad popular, independientemente de sus contenidos, y 2) una sustancial a partir del reconocimiento de los derechos humanos, el principio de igualdad, no discriminación, entre otros. Ahora bien, ambas dimensiones, lejos de contraponerse, en realidad se complementan, de tal manera que la integración de ambas dimensiones da como resultado el modelo denominado democracia constitucional, representando un modelo normativo multidimensional: 1) democracia política; 2) democracia civil; 3) democracia liberal y 4) democracia social. En conclusión, la democracia constitucional representa un modelo integral, al considerar las dimensiones formal y sustancial, así como determinando ciertas obligaciones de las cuales el Estado no puede eludirse, estas, que se encuentran orientadas a alcanzar el verdadero orden social por el cual fue creado el Estado y dotado de poder. Este modelo se reinventa sobre las bases democráticas al incorporar progresivamente el reconocimiento de nuevos derechos, tanto de fuente nacional como 
internacional, y, como veremos más adelante, los procesos de justicia transicional deben estar orientados a la consolidación de dicho modelo.

\section{Bloque de constitucionalidad y democracia constitucional}

Luego de analizar detenidamente las características del modelo denominado democracia constitucional y de precisar su estructura básica compuesta por derechos de naturaleza liberal, civil, política y social, corresponde el turno de resaltar algunos rasgos que se incorporan a este modelo desde el orden internacional de los derechos humanos.

Ahora bien, el Derecho Internacional de los Derechos Humanos cobró relevancia al finalizar la Segunda Guerra Mundial, trayendo como consecuencia la proclamación de la Declaración Universal de los Derechos Humanos, en cuyo preámbulo se precisó que el desconocimiento y el menosprecio de los derechos representan la consecuencia de los lamentables actos de barbarie; por lo que, atendiendo a un ideal común, se asumieron compromisos de promoción, enseñanza, respeto, garantía, así como de reconocimiento y aplicación universales (A.G. NU, 1948,

En ese sentido, las constituciones de los Estados-parte incorporaron cláusulas de recepción del derecho internacional en el derecho interno, dando como resultado un robusto corpus iuris de derechos humanos, tanto de orden nacional como de orden internacional, a esta incorporación -que reconoce en una misma jerarquía tanto al orden constitucional como el orden internacional de los derechos humanos-, se le ha denominado bloque de constitucionalidad. Dichas cláusulas constitucionales de recepción podemos identificarlas a nivel regional en los siguientes artículos:

- Argentina: reconoce la vigencia de un bloque de constitucionalidad conformado por un delimitado catálogo de tratados (art. 75 inciso 22). 
- Colombia: los tratados y convenios internacionales que reconocen los derechos humanos y que prohíben su limitación en los estados de excepción prevalecen en el orden interno (art. 93).

- México: todas las personas gozarán de los derechos reconocidos en esta Constitución y en los tratados internacionales de los que el Estado mexicano sea parte. La Constitución, las leyes del Congreso de la Unión y los tratados serán la ley suprema de toda la Unión (arts. $1 .^{\circ}$ y 133).

- Perú: los tratados celebrados por el Estado y en vigor forman parte del derecho nacional (arts. $3 \cdot^{\circ}$ y 55 ).

Cabe señalar que, además, el bloque de constitucionalidad ha sido desarrollado por vía jurisprudencial en distintos países, por ejemplo, la Corte Constitucional de Colombia afirmó que esta figura representa el parámetro de control, integrado no solo por normas, sino también por principios:

El bloque de constitucionalidad está compuesto por aquellas normas y principios que, sin aparecer formalmente en el articulado del texto constitucional, son utilizados como parámetros del control de constitucionalidad de las leyes, por cuanto han sido normativamente integrados a la Constitución, por diversas vías y por mandato de la propia Constitución. Son pues verdaderos principios y reglas de valor constitucional, esto es, son normas situadas en el nivel constitucional, a pesar de que puedan a veces contener mecanismos de reforma diversos al de las normas del articulado constitucional stricto sensu. (C.C., Sentencia C-225/1995, Colom.)

Tan solo unos cuantos años después, la Corte Constitucional de Colombia precisó que el bloque de constitucionalidad "estaría conformado no sólo por el articulado de la Constitución sino, entre otros, por los tratados internacionales de que trata el artículo 93 de la Carta, por las leyes 
orgánicas y, en algunas ocasiones, por las leyes estatutarias” (C.C., Sentencia C-191/1998, Colom.).

Para concluir con este apartado hemos de precisar que vivimos en tiempos de constante transformación, y estas evoluciones, o involuciones, se reflejan en el marco jurídico nacional e internacional, principalmente en nuestras constituciones, comprendiendo a estas como leyes supremas -al menos en un primer momento-.

De tal manera que los tribunales constitucionales -comprendidos como órganos de cierre dentro de un Estado-, no siempre actúan bajo los principios de progresividad y máxima protección; lo que se corrobora en interpretaciones restrictivas injustificadamente. Es decir, frente a los avances constitucionales y legislativos, siempre se corre el peligro del retroceso por vía jurisprudencial, y nos corresponde levantar la voz, acompañados por la razón, cuando se vulnere ese corpus iuris de los derechos humanos.

\section{La justicia transicional hacia la democracia constitucional}

Hemos reiterado que la democracia constitucional implica una participación activa de los ciudadanos en la toma de decisiones, además del respeto y garantía de sus derechos -civiles, políticos, sociales, libertades, etc.-, pero, ¿̇qué sucede cuando se abandona un régimen militar o demo-autoritario?, ¿cómo se castigan los abusos del pasado?, ¿qué sucede con las víctimas de graves delitos?, ¿cómo se reconstruye el tejido social?

Cada una de las interrogantes forma parte de la justificación de la denominada justicia transicional, una especie de bisagra entre el autoritarismo y la democracia. Advertimos que no representa un modelo completamente definido, sino un modelo en constante construcción, 
dependiendo de cada realidad y contexto en el que se pretenda implementar un sistema democrático (Ortega y García, 2019).

Por ejemplo, el secretario general de la Organización de las Naciones Unidas en su informe S/2004/616, denominado El Estado de derecho y la justicia de transición en las sociedades que sufren o han sufrido conflictos (2004), precisó que la justicia transicional implica:

[T]oda la variedad de procesos y mecanismos asociados con los intentos de una sociedad por resolver los problemas derivados de un pasado de abusos a gran escala, a fin de que los responsables rindan cuentas de sus actos, servir a la justicia y lograr la reconciliación. Tales mecanismos pueden ser judiciales o extrajudiciales y tener distintos niveles de participación internacional (o carecer por complejo de ella) así como abarcar el enjuiciamiento de personas, el resarcimiento, la búsqueda de la verdad, la reforma institucional, la investigación de antecedentes, la remoción del cargo o combinaciones de todos ellos. (p. 6)

Posteriormente, el secretario general de la ONU, en su informe denominado Aunar nuestras fuerzas para fortalecer el apoyo de las Naciones Unidas al estado de derecho (2006), afirmó con fuerza que el Estado de derecho y la justicia de transición correspondían a una misma categoría, al igual que los elementos de justicia, paz y democracia se caracterizan por una relación de interdependencia. Teniendo en cuenta tales parámetros, las actividades que configuran a la justicia de transición corresponden a "procesos nacionales de consulta sobre justicia de transición, procesos de verdad y reconciliación, indemnizaciones, tribunales internacionales y mixtos, instituciones nacionales de derechos humanos, procesos de veto e investigaciones especiales, determinación de los hechos y comisiones de investigación" (2006, párr. 41). Asimismo, podemos encontrar que en el informe anual del Alto Comisionado de las Naciones Unidas para los Derechos Humanos e 
informes de la Oficina del Alto Comisionado y del Secretario General denominado Estudio analítico de los derechos humanos y la justicia de transición (2009), se precisó que la justicia de transición "debe tratar más ampliamente las causas profundas de los conflictos y las violaciones conexas de todos los derechos, incluidos los derechos civiles, políticos, económicos, sociales y culturales" (párr. 3).

De tal manera que podríamos continuar exponiendo el desarrollo de los alcances de la justicia de transición desde los lineamientos establecidos por la ONU; sin embargo, nos interesa centrar la atención en las más recientes directrices precisadas en la resolución $\mathrm{A} / \mathrm{HRC} / 42 / \mathrm{L} .2 \mathrm{O}$, tal y como se presenta a continuación:

1. Los enjuiciamientos individuales.

2. La reparación.

3. La búsqueda de la verdad.

4. La reforma institucional.

5. La investigación de los antecedentes de los empleados o funcionarios públicos.

6. Las iniciativas de preservación de la memoria.

7. Garantizar la rendición de cuentas.

8. Fomentar la recuperación de la normalidad y la reconciliación

9. Establecer entidades independientes que supervisen los sistemas de seguridad.

10. Restablecer la confianza en las instituciones del Estado y promover el Estado de derecho de conformidad con la normativa internacional de derechos humanos y el derecho internacional humanitario.

A manera de síntesis, la justicia transicional se conforma por el conjunto de mecanismos judiciales y extrajudiciales que tienen por objetivo consolidar la democracia constitucional, luego de abandonar un régimen opresor y superar un conflicto social que haya implicado una serie de 
abusos y violencias estructurales; a través de la búsqueda de la verdad, la justicia en su más amplio sentido, la reparación integral a cada una de las víctimas, la reforma institucional, la recuperación y preservación de la memoria, promoviendo en todo momento las acciones tendientes a la reconciliación nacional dentro de un marco normativo respetuoso de los derechos humanos (Velandia y Sánchez, 2020).

Ahora bien, desde perspectiva científica, Jon Elster (2006) sostiene que la justicia transicional "se compone de los procesos de juicios, purgas y reparaciones que tienen lugar luego de la transición de un régimen político a otro" (p. 15).

En ese mismo sentido, Ruti G. Teitel (2014) ubica a la justicia transicional en el marco de los periodos de cambio político, y que se caracteriza por dar respuestas legales a las malas acciones de los regímenes represivos del pasado, precisando que en este milenio este modelo de justicia ha dejado de ser extraordinario para convertirse en una justicia relativamente ordinaria, ante un contexto mundial que se enfrenta cotidianamente a la debilidad estatal, fragmentación política, guerras pequeñas y conflictos constantes.

Si observamos con detenimiento, podremos advertir que la justicia transicional tiene un punto de partida en el momento en que una sociedad que ha vivido una serie de abusos en el pasado y a gran escala, demanda una transformación institucional que permita la investigación de crímenes, la protección a las víctimas, la sanción a los responsables y la reparación integral. Lo anterior como resultado de un proceso de reformas, tanto legales como constitucionales, que permitan alcanzar ciertos estándares democráticos, evidenciando la relación entre la democracia constitucional y la justicia transicional. 


\section{Desarrollo jurisprudencial de la Corte Interamericana de Derechos Humanos aplicable en el contexto de la justicia transicional}

Aunque pareciera obvio, resulta importante resaltar que la implementación de un modelo de justicia transicional representa 1) el reconocimiento de una deuda social por parte del Estado y 2) el desarrollo de una serie de acciones tendientes a saldar dicha deuda.

En efecto, Paige (2011) reconoce el desarrollo de la justicia transicional en América Latina -además de Europa y África-, a raíz de las graves violaciones a los derechos humanos que se cometieron bajo las dictaduras del siglo pasado, tales como la desaparición forzada, la ejecución extrajudicial, la detención arbitraria y la tortura, por citar solo algunas. De ahí que los derechos a la verdad, la justicia, la reparación y la no repetición, representen los pilares estructurales de este modelo de justicia.

Si se fija la atención en América Latina, sería un error omitir que además del Sistema Universal de Derechos Humanos, se ha desarrollado un Sistema Regional de Protección que tiene origen en la Carta de la Organización de los Estados Americanos (1948). Casi dos décadas después, los Estados-parte acordaron la proclamación de la Convención Americana sobre Derechos Humanos "Pacto de San José de Costa Rica" (1969) que, sin lugar a dudas, al día de hoy representa en tratado más importante en materia de derechos humanos en el contexto latinoamericano.

La afirmación anterior se justifica atendiendo a que la Convención Americana retoma los principios de democracia, libertad, justicia y paz (Huertas, López y Jerez, 2019). Además, en su artículo 33 establece los dos órganos de control del sistema, la Comisión Interamericana y la Corte Interamericana, siendo esta última la autoridad contenciosa que puede condenar a un Estado-parte al incumplir las obligaciones establecidas en todo el corpus iuris interamericano. 
De tal manera que, una vez agotados los procedimientos establecidos en los artículos 48 al 50, y reconocida la competencia contenciosa de la Corte a la que hace referencia el artículo 62 de la Convención Americana, se procederá al análisis de los casos sometidos a su jurisdicción y en caso de identificar violaciones a los derechos humanos, se procederá a dictar un fallo, el cual los Estados-parte se comprometen a cumplir de acuerdo con el artículo 68 de este instrumento internacional.

Las sentencias de la Corte Interamericana han tenido gran impacto durante los últimos treinta años, provocando enormes tensiones en los Estados-parte, aun cuando estos se hayan comprometido antes a cumplir con lo ordenado en las sentencias. Así, por ejemplo, en Colombia, la Corte Constitucional ha precisado lo siguiente:

Resalta la Corte Constitucional, la función jurisdiccional de la Corte IDH se enmarca, entre otros objetivos, dentro del artículo 22 de nuestra Constitución, que reconoce la paz como un derecho y un deber de obligatorio cumplimiento. Si así es, el acatamiento de las decisiones emanadas de los tribunales internacionales es una garantía de paz. Ahora bien, los derechos humanos reconocidos en la Convención pertenecen a lo que esta Corte ha llamado bloque de constitucionalidad en sentido estricto. De acuerdo con el contenido del artículo 93 superior, las normas que contiene se entienden incorporadas al ordenamiento interno y surten efectos directos. Al aplicar el concepto de bloque de constitucionalidad, la declaratoria que hacen los jueces de la Corte IDH no solo repercute sobre la esfera internacional sino sobre el ordenamiento interno. Así, la violación declarada por la Corte Interamericana surte efectos en el ámbito de las relaciones entre países soberanos y miembros de la OEA donde se reconoce a la nación como infractora- $\mathrm{y}$, a la vez, proyecta directamente consecuencias dentro del Estado. En diversos fallos esta Corporación se ha referido puntualmente a la Corte IDH, indicando que su jurisprudencia es un criterio relevante para fijar el parámetro de control de las normas que hacen parte del ordenamiento interno

Via Inveniendi Et Iudicandi

e-ISSN: 1909-0528 | DOI: https://doi.org/10.15332/19090528

Vol. 16 N.o 2 | julio-diciembre del 2021 
colombiano, precisamente porque establece el alcance de distintos instrumentos internacionales de derechos humanos. La Corporación ha sostenido que la jurisprudencia de la Corte IDH contiene la interpretación auténtica de los derechos contenidos en la Convención Americana sobre Derechos Humanos, instrumento internacional que integra el parámetro de control de constitucionalidad. (Corte Constitucional, 2012, Sentencia T-653)

Por su parte, la Suprema Corte de Justicia de la Nación en México sostuvo que las interpretaciones de la Corte Interamericana forman parte del parámetro de regularidad constitucional, figura que se equipara al bloque de constitucionalidad, tal y como se transcribe a continuación:

Parámetro de regularidad constitucional. Se extiende a la interpretación de la norma nacional o internacional. Las autoridades judiciales deben aplicar el parámetro de regularidad constitucional incluidos, por supuesto, los estándares sobre derechos humanos-, lo cual, claramente, no se limita al texto de la norma - nacional o internacional- sino que se extiende a la interpretación que hagan los órganos autorizados -tribunales constitucionales y organismos internacionales según corresponda-. Al respecto, la Corte Interamericana ha establecido que "los órganos del Poder Judicial deben ejercer no sólo un control de constitucionalidad, sino también de convencionalidad ex officio entre las normas internas y la Convención Americana”. En similar sentido, el Pleno de esta Suprema Corte de Justicia estableció, en la Contradicción de Tesis 21/2011, que "el control de convencionalidad es un control de constitucionalidad desde el punto de vista sustantivo, dada la interpretación material que se hace del artículo 10. constitucional”. (Suprema Corte de Justicia de la Nación, 2015)

De los criterios emanados de las Altas Cortes, tanto en Colombia, así como en México, se identifica la reiteración de la fuerza vinculante de las interpretaciones - recordemos la función consultiva- y de las sentencias 
de la Corte Interamericana, además de incorporarlas en el bloque de constitucionalidad y en el parámetro de regularidad constitucional, respectivamente. Estas decisiones en sede nacional representan el resultado de una transformación en la cultura jurídica y en las propias fuentes del derecho contemporáneas, apartándose de ciertas tensiones aparentemente fundamentadas en la violación al principio de soberanía; abonando entonces a la construcción de directrices globales y regionales para hacer frente a los problemas que rebasan en muchas ocasiones las propias fronteras (Blanco, 2013).

Resulta así necesario complementar las directrices de la justicia transicional a partir de los desarrollos jurisprudenciales aplicables de manera indirecta en este modelo de justicia en el ámbito interamericano. Precisamos esa naturaleza indirecta, toda vez que países como Argentina, Brasil, Colombia, México, Perú, entre otros, han sido condenados por la Corte Interamericana ante el incumplimiento del deber de respeto y garantía de los derechos humanos, tales como el derecho a la vida, a la protección judicial, a libertad e integridad personal, garantías del debido proceso, siendo estos los pilares de la multicitada justicia transicional.

\section{Derecho a la justicia}

En cuanto a este derecho, la Corte Interamericana ha reiterado, en su jurisprudencia, que la participación de las víctimas en los procesos penales no debe centrarse exclusivamente en la reparación del daño, sino además en el conocimiento de la verdad y al acceso a la justicia ante tribunales competentes, debiendo contar en todo momento con herramientas efectivas para impugnar la competencia de un tribunal que no se encuentre facultado para conocer del asunto (Corte IDH, 2006, Fernández Ortega y otros vs. Méx.). 
Continuando, la Corte Interamericana ha señalado que el acceso a la justicia por parte de las víctimas implica que se haga todo lo necesario para conocer la verdad de lo sucedido e investigar, juzgar y, en su caso, sancionar a los eventuales responsables, dentro de un tiempo razonable, debiendo suministrar recursos judiciales efectivos y sustanciado de conformidad con las reglas del debido proceso (Corte IDH, 2018, López Soto y otros vs. Venez.).

Ha insistido en la obligación que tienen los Estados-parte de garantizar el derecho de acceso a la justicia dentro de un plazo razonable, cuyo incumplimiento traería como consecuencia la condena internacional, al violar de manera indiscutible las propias garantías judiciales (Corte IDH, 2018, Ramírez Escobar y otros vs. Guat.). Es así que se han establecido cuatro elementos a tener en cuenta:

1. Complejidad del asunto.

2. La actividad procesal del interesado.

3. La conducta de las autoridades.

4. La afectación generada en la situación jurídica de la persona involucrada en el proceso.

Ciertamente, estos parámetros definidos por la propia Corte Interamericana resultan aplicables a la mayoría de los asuntos sometidos a su conocimiento, ya que el derecho de acceso a la justicia ha sido violentado, tanto en los regímenes más autoritarios, como en las propias democracias, ya sea por una demora injustificada para resolver un asunto, o por no existir un tribunal autónomo y competente para conocer de la posible violación de uno o varios derechos, o un recurso efectivo para impugnar las decisiones que se consideren injustificadas. 


\section{Derecho a la verdad}

Cuando nos referimos a un proceso de justicia transicional no podemos prescindir del derecho a conocer la verdad. Es así que la Corte Interamericana ha reiterado en su jurisprudencia que el Estado-parte debe garantizar la participación de las víctimas o familiares en todas las etapas de investigación y juzgamiento de los responsables, teniendo como finalidad el acceso a la justicia y al conocimiento de la verdad.

Recientemente, la Corte sostuvo que los resultados de dichos procesos deben ser publicados para que la sociedad conozca los hechos y los responsables (Corte IDH, 2018, Alvarado Espinoza y otros vs. Méx.).

Años atrás, la Corte ya había sostenido que los Estados-parte tienen la obligación de combatir toda situación de impunidad, ya que propicia la repetición de violaciones e indefensión. Por lo tanto, se reconoció el derecho de las víctimas y de los familiares a conocer toda la verdad de los hechos, además de los responsables de estos, constituyendo, al mismo tiempo, un medio importante de reparación (Corte IDH, 2006, La Cantuta vs. Perú).

En relación con lo anterior, la Corte ha advertido que el derecho de acceso a la información cobra una especial relevancia en aquellos casos que implican violaciones de derechos humanos, como consecuencia, el Estadoparte no puede restringir este derecho, ni aun aduciendo razones de interés público o seguridad nacional, ya que este resulta imprescindible para que los órganos administrativos y judiciales lleven a cabo investigaciones adecuadas para responder a la exigibilidad de los derechos de las víctimas (Corte IDH, 2015, Omar Humberto Maldonado Vargas y otros vs. Chile).

El propio devenir histórico se ha encargado de corroborarnos que el reconocimiento de un derecho, acompañado del compromiso por parte de 
un Estado de respeto y garantía, nunca ha resultado suficiente, de ahí la necesidad de mecanismos procesales judiciales o administrativos para su adecuada materialización (Buitrago, 2019).

En ese sentido, la Corte Interamericana ha precisado en su jurisprudencia que los Estados pueden establecer comisiones de la verdad, siendo que estas contribuyen a 1) la construcción y preservación de la memoria histórica, 2) al esclarecimiento de hechos y 3) a la determinación de responsabilidades. Sin embargo, a la par deben seguir existiendo los procesos judiciales (Corte IDH, 2012, Masacres de el Mozote y lugares aledaños vs. El Salv.).

\section{Derecho a la reparación}

Siguiendo con el análisis de la jurisprudencia de la Corte Interamericana, esta ha establecido que el derecho a la reparación de las víctimas debe tener un nexo causal con 1) los hechos del caso, con 2) las violaciones declaradas, con 3) los daños acreditados y con 4) las medidas solicitadas de la reparación misma. Todo lo anterior, teniendo en cuenta la perspectiva de género, tanto en la formulación, como en la implementación (Corte IDH, 2018, López Soto y otros vs. Venez.).

Cabe señalar que existen asuntos en los que resulta imposible la plena restitución de los derechos, es decir, el restablecimiento de la situación hasta antes de la violación o violaciones a los derechos. Por lo tanto, la propia autoridad judicial es quien determinará las medidas para garantizar la reivindicación de derechos y la reparación en sí (Corte IDH, 2015, Granier y otros (Radio Caracas Televisión) vs. Venez.). No se debe olvidar que, durante el siglo pasado, en América Latina, se cometieron graves violaciones de derechos a partir del despliegue de la 
fuerzas militares en los regímenes autoritarios de países como Brasil, Argentina, Chile, Colombia, México, Perú, entre otros.

No resulta una casualidad que gran parte de las sentencias de la Corte Interamericana tienen su fundamento en la violación a los derechos a la vida y a la libertad personal, cobrando vigencia la figura de desaparición forzada. Esto trajo como consecuencia, en el ámbito regional, la creación de la Convención Interamericana sobre Desaparición Forzada de Personas (1994), estableciendo un estándar que permitiera a los Estados-parte tipificar adecuadamente esta lamentable conducta, quedando de la siguiente manera:

Artículo 2. A los efectos de la presente Convención, se entenderá por "desaparición forzada" el arresto, la detención, el secuestro o cualquier otra forma de privación de libertad que sean obra de agentes del Estado o por personas o grupos de personas que actúan con la autorización, el apoyo o la aquiescencia del Estado, seguida de la negativa a reconocer dicha privación de libertad o del ocultamiento de la suerte o el paradero de la persona desaparecida, sustrayéndola a la protección de la ley.

Como se puede observar, la desaparición forzada solo puede llevarse a cabo por agentes del Estado o particulares bajo la protección de este, implicando un ocultamiento de una persona o la negativa de dar información sobre su paradero, poniendo a la víctima en un estado de completa indefensión.

En este contexto, la Corte Interamericana ha precisado que el derecho de los familiares de las víctimas, de conocer los restos de sus seres queridos, representa una medida de reparación per se, además de guardar relación con el derecho a conocer la verdad (Corte IDH, 2012, Nadege Dorzema y otros vs. R. Dom.). 


\section{Garantías de no repetición}

De acuerdo con Luigi Ferrajoli (2018), "garantía es una expresión del léxico jurídico que designa cualquier técnica normativa de tutela de un derecho subjetivo" (p. 21). Las garantías resultan imprescindibles, ya que su ausencia representa un inminente peligro para un derecho subjetivo - esta expresión puede ser utilizada para los derechos humanos y fundamentales-.

Por ello, resulta necesario advertir que existen garantías primarias que corresponden a las obligaciones y prohibiciones frente a los derechos humanos; mientras que, por otra parte, las garantías secundarias o jurisdiccionales recaen sobre los órganos encargados de aplicar una sanción ante la comisión de un acto ilícito, o declarar la nulidad de los actos que atenten contra los derechos de las personas (2018, pp. 24-25). Las garantías de no repetición corresponden a la tipología de garantías primarias y secundarias, ya que no se limitan al reconocimiento de un derecho o al control de legalidad por parte de una autoridad, incluso las garantías de no repetición, en muchas ocasiones, podrían materializarse en políticas públicas.

A diferencia de los asuntos analizados en los apartados anteriores, la Corte Interamericana, en el 2014, condenó a la República Dominicana por haber expulsado de su territorio a un grupo de personas de origen haitiano en situación de vulnerabilidad, así como de personas nacidas en territorio dominicano, negándoles a estos últimos su derecho a la nacionalidad. Por lo que la Corte señaló en su jurisprudencia que, en ese tipo de casos, las garantías de no repetición cobran una gran relevancia para que dichas violaciones no se repitan, debiendo adoptar 1) medidas legislativas, 2) medidas administrativas y 3) medidas diversas para garantizar el ejercicio 
de los derechos (Corte IDH, 2014, personas dominicanas y haitianas expulsadas vs. R. Dom.).

Tan solo un año después, la Corte Interamericana precisó que las garantías de no repetición podrían abarcar medidas enfocadas a la capacitación de agentes del Estado para erradicar las violaciones a los derechos. Estas implicaron:

1. La capacitación de policías, fiscales y jueces en materia de prevención, investigación y sanción de la tortura.

2. La creación de un programa o curso permanente y obligatorio sobre derechos humanos, incluyendo la perspectiva de género y niñez.

3. La implementación de programas permanentes de derechos humanos dirigidos a policías, fiscales, jueces y militares, así como a funcionarios encargados de la atención a familiares y víctimas de desaparición forzada de personas (Corte IDH, 2015, Ruano Torres y otros vs. El Salv.).

De lo anterior, se observa la especial relevancia de los artículos 1 y 2 de la Convención Americana, en los que se establece el reconocimiento de un catálogo de derechos que se extiende hasta el resto de instrumentos que conforman el corpus iuris interamericano, así como las obligaciones de respeto y garantía de los derechos humanos, a las que los Estados-parte se comprometieron cumplir (Cabrera, 2020).

No cabe la menor duda de que una transformación constitucional o legislativa siempre tendrá un considerable impacto en la sociedad, pero existen transformaciones más profundas que son las sustanciales, pudiendo ubicar a las transformaciones culturales como subcategoría, y que resultan ser, en no pocas ocasiones, las mejores garantías de prevención a las violaciones de los derechos humanos. 


\section{Conclusiones}

La democracia constitucional representa el modelo de Estado completo y sobre todo congruente con los compromisos que implican las obligaciones de respeto y garantía de los derechos humanos. Un modelo muy por encima de lo que hemos conocido como el simple Estado de derecho, y que, a partir de este, se justificaron las más aberrantes violaciones en el siglo XX.

Durante las últimas tres décadas en la región latinoamericana tuvieron lugar significativas transformaciones políticas y sociales, principalmente, orientadas a sustituir los regímenes autoritarios por las democracias. Desde el ámbito internacional, la Carta de los Estados Americanos y los diferentes tratados influyeron en las constituciones latinoamericanas, dando como resultado figuras como el bloque de constitucionalidad que hicieron ineludibles las responsabilidades contraídas por los Estadosparte.

Gran parte de los países latinoamericanos se han enfrentado a graves dificultades para desarrollar un sistema democrático, ya sea porque arrastran conflictos sociales o políticos del pasado, o porque se enfrentan a otros grandes retos contemporáneos, como la desigualdad, la ausencia de paz y las crisis económicas derivadas de modelos como el neoliberalismo.

La justicia transicional representa, en estos contextos, una alternativa pacífica para la consolidación democrática, enfrentándose a ciertas distorsiones del principio de legalidad en el contexto de la transición.

No obstante, el modelo de transición surge a partir de cambios constitucionales y legales que encuentran fundamento en principios democráticos como la libertad, la igualdad, la protección a las víctimas, la reparación y la reconstrucción del tejido social. 
La experiencia comparada nos permite analizar las principales líneas jurisprudenciales en la construcción y revisión de los modelos de justicia transicional. Lo que se traduce en lineamientos en los que las víctimas desempeñan un especial rol en materia de protección y garantía de los derechos humanos.

Hoy en día, los Estados que buscan consolidarse como democracias reconocen las deudas pendientes con las víctimas de las graves violaciones, reconociéndoseles derechos como la verdad, la justicia, la reparación y las garantías de no repetición, generando las condiciones necesarias para trasladar el amplio catálogo de derechos humanos que se encuentra en el papel, a la realidad y consolidando ese modelo integral de Estado que denominamos democracia constitucional.

\section{Referencias}

A.G. Declaración Universal de los Derechos Humanos. NU (1948).

Andreopoulos, G. J., Barberet, R. L. y Nalla, M. K. (2018). Introduction: Rule of Law in an Era of Change. Challenges and Prospects. En G. J. Andreopoulos, R. L. Barberet y M. K. Nalla (eds.), The Rule of Law in an Era of Change. Responses to Transnational Challenges and Threats (pp. 1-14). Springer.

Asamblea Nacional de Francia. Declaración de los Derechos del Hombre y del Ciudadano (1789).

Asamblea Nacional de Weimar. Constitución del Reich Alemán (11 de agosto de 1919).

Blanco, C. (2013). Aproximación a la noción de soberanía estatal en el marco del proceso andino de integración. Revista Republicana, (15), 91-103.

Blanco, C. (2020). El recordatorio a la determinación del contenido esencial de los derechos fundamentales, atendiendo el escenario de la pandemia por el covid-19 en el Estado colombiano. Revista Novum Jus, 15(1), 17-40.

https://doi.org/10.14718/NovumJus.2021.15.1.2

Via Inveniendi Et Iudicandi

e-ISSN: 1909-0528 | DOI: https://doi.org/10.15332/19090528

Vol. 16 N.० 2 | julio-diciembre del 2021 
Borbón, J. A. (2019). La política de defensa y seguridad democrática en el Estado social de derecho. Revista IUSTA, 1(50), 97-120. https://doi.org/10.153332/1900$\underline{0448.2019 .0050 .04}$

Buitrago, W. F. (2019). Los mecanismos de reparación a víctimas y su incidencia en la restitución de tierras en Colombia. Via Inveniendi Et Iudicandi, 14(2), 119-143. https://doi.org/10.15332/19090528/5041

Cabrera, J. (2020). La política criminal vista desde la justicia restaurativa en México. Via Inveniendi et Iudicandi, 15(1), 161-187. https://orcid.org/0000-0002-1081$\underline{0424}$

Carta OEA. 30 de abril de 1948.

Caso Fernández Ortega y otros vs. México. Excepción Preliminar, Fondo, Reparaciones y Costas, Sentencia del 30 de agosto de 2010. Serie C No. 215.

Caso La Cantuta vs. Perú. Fondo, Reparaciones y Costas. Sentencia del 29 de noviembre de 2006. Serie C. No. 162.

Caso Masacres de El Mozote y lugares aledaños vs. El Salvador. Fondo, Reparaciones y Costas. Sentencia del 25 de octubre de 2012. Serie C No. 252.

Caso Nadege Dorzema y otros vs. República Dominicana. Fondo, Reparaciones y Costas. Sentencia del 24 de octubre de 2012. Serie C No. 251.

Caso de personas dominicanas y haitianas expulsadas vs. República Dominicana. Excepciones Preliminares, Fondo, Reparaciones y Costas. Sentencia del 28 de agosto de 2014 Serie C No. 282.

Caso Omar Humberto Maldonado Vargas y otros vs. Chile. Fondo, Reparaciones y Costas. Sentencia del 2 de septiembre de 2015. Serie C No. 300.

Caso Granier y otros (Radio Caracas Televisión) vs. Venezuela. Excepciones Preliminares, Fondo, Reparaciones y Costas. Sentencia del 22 de junio de 2015. Serie C No. 293.

Caso Ruano Torres y otros vs. El Salvador. Fondo, Reparaciones y Costas. Sentencia del 5 de octubre de 2015. Serie C No. 303.

Caso López Soto y otros vs. Venezuela. Fondo, Reparaciones y Costas. Sentencia del 26 de septiembre de 2018. Serie C No. 362.

Via Inveniendi Et Iudicandi

e-ISSN: 1909-0528 | DOI: https://doi.org/10.15332/19090528

Vol. 16 N.० 2 | julio-diciembre del 2021 
Caso Ramírez Escobar y otros vs. Guatemala. Fondo, Reparaciones y Costas. Sentencia del 9 de marzo de 2018. Serie C No. 351.

Caso Alvarado Espinoza y otros vs. México. Fondo, Reparaciones y Costas. Sentencia del 28 de noviembre de 2018. Serie C No. 370.

Constitución Política de Colombia [C.P.]. 1991, (Colom.).

Constitución Política de los Estados Unidos Mexicanos [C.P.]. 1917, (Méx.).

Corte Constitucional de Colombia [C.C.]. 18 de mayo de 1995, M.P.: A. Martínez Caballero, Sentencia C-225, [Colom.].

Corte Constitucional de Colombia [C.C.]. 6 de mayo de 1998, M.P.: E. Cifuentes Muñoz, Sentencia C-191, [Colom.].

Corte Constitucional de Colombia [C.C.]. 23 de agosto de 2012, M.P.: J. I. Palacio Palacio, Sentencia T-653, [Colom.].

Elster, J. (2006). Rendición de cuentas: la justicia transicional en perspectiva histórica. Katz.

Ferrajoli, L. (2009). Pasado y futuro del estado de derecho. En M. Carbonell (ed.), Neoconstitucionalismo(s) $\left(4 \cdot^{\mathrm{a}} \mathrm{ed}\right.$.). Trotta.

Ferrajoli, L. (2013). Principia iuris. Teoría del derecho y de la democracia. 2. Teoría de la democracia. Trotta.

Ferrajoli, L. (2018). El paradigma garantista. Filosofía crítica del derecho penal. Trotta.

Ferrajoli, L. y Bovero, M. (2012). Teoría de la democracia. Dos perspectivas comparadas. Instituto Federal Electoral de México (I.F.E.).

Hernández, M. (2015). Aplicación del bloque de constitucionalidad por la Corte Suprema de Justicia en el concepto emitido en el trámite de extradición a los postulados de justicia y paz. Ibáñez.

Huertas, O., López, D. y Jerez, A., L. S. (2019). La “paz” como escenario de disputa ideológica. Revista IUSTA, (50), 19-38. https://doi.org/10.15332/1900$\underline{0448.2019 .0050 .01}$

Juan I de Inglaterra. Magna Carta Libertatum. 15 de junio de 1215.

Via Inveniendi Et Iudicandi

e-ISSN: 1909-0528 | DOI: https://doi.org/10.15332/19090528

Vol. 16 N.o 2 | julio-diciembre del 2021 
Kelsen, H. (2001). La garantía jurisdiccional de la Constitución. La justicia constitucional. Instituto de Investigaciones Jurídicas de la Universidad Nacional Autónoma de México.

Manrique, F. E. (2019). Hacia la generación de un ius anticorruptionis commune en Latinoamérica. Iustitia(17), 9-23. https://doi.org/10.15332/iust.voi17.2419

NU. S/2004/616. Informe del Secretario General. El Estado de derecho y la justicia de transición en las sociedades que sufren o han sufrido conflictos. 3 de agosto de 2004.

NU. S/2006/980. Asamblea General. Aunar nuestras fuerzas para fortalecer el apoyo de las Naciones Unidas al estado de derecho. 14 de diciembre de 2006.

NU. A/HRC/12/18. Informe anual del Alto Comisionado de las Naciones Unidas para los Derechos Humanos e informes de la Oficina del Alto Comisionado y del Secretario General. Estudio analítico de los derechos humanos y la justicia de transición. 6 de agosto de 2009.

NU. A/HRC/42/L.20. Asamblea General. Promoción y protección de todos los derechos humanos, civiles, políticos, económicos, sociales y culturales, incluido el derecho al desarrollo. 24 de septiembre de 2019.

OEA. Declaración Americana de los Derechos y Deberes del Hombre. Novena Conferencia Internacional Americana, 30 de marzo a 2 de mayo de 1948.

OEA. Convención Americana sobre Derechos Humanos. Conferencia Especializada Interamericana Sobre Derechos Humanos (B-32). 7 a 22 de noviembre de 1969.

OEA. Convención Interamericana sobre Desaparición Forzada de Personas (A-60). 9 de junio de 1994 .

Ortega, L. G. y García, J. P. (2019). La verdad en la justicia transicional. Revista IUSTA, 1(50), 39-63. https://doi.org/10.15332/1900-0448.2019.0050.02

Paige, A. (2011). Introduction: Identities in Transition. En A. Paige (ed.), Identities in Transition: Challenges for Transitional Justice in Divided Societies. Cambridge University Press.

Suprema Corte de Justicia [S.C.J.N.], Tesis 1a. CCCXLIV/2015 (10.å), 2015, [Méx.]

Suprema Corte de Justicia [S.C.J.N.], Tesis P./J 20/2014. 2014, [Méx.].

Via Inveniendi Et Iudicandi

e-ISSN: 1909-0528 | DOI: https://doi.org/10.15332/19090528

Vol. 16 N.o 2 | julio-diciembre del 2021 
Teitel, R. G. (2014). Globalizing transitional justice: contemporary essays. Oxford University Press.

Velandia, J. y Sánchez, M. E. (2020). ¿Cuál es la metodología para consolidar datos en una cultura de paz y reconciliación en Colombia? Revista Via Inveniendi et Iudicandi, 15(2), 131-163. https://doi.org/10.15332/19090528/6245

Zagrebelsky, G. (2011). El derecho dúctil. Ley, derechos y justicia (10. ${ }^{\mathrm{a}}$ ed.). Trotta.

Via Inveniendi Et Iudicandi

e-ISSN: 1909-0528 | DOI: https://doi.org/10.15332/19090528

Vol. 16 N.0 2 | julio-diciembre del 2021 